\title{
Changes to the gastrointestinal microbiota in pediatric acute lymphoblastic leukemia: A literature review
}

\author{
Zuzanna Zakrzewska ${ }^{1}$, Szymon Skoczen ${ }^{1}$, Małgorzata Czogała $^{2}$, and Wojciech Czogała ${ }^{2}$ \\ ${ }^{1}$ Jagiellonian University in Kraków Medical College \\ ${ }^{2}$ Department of Pedriatric Oncology and Hematology, Jagiellonian University Medical \\ College
}

September 25, 2021

\begin{abstract}
The human microbiota, which consists of trillions of microorganisms, impacts the host's health and treatment of potential diseases. The role of the microbiota in the development and treatment of childhood leukemia is still not clear. This study reviews the current scientific understanding of the changes in gut microbiota composition during chemotherapy in acute lymphoblastic leukemia (ALL) in children and assesses its impact on the treatment process. The findings show alterations in gut microbiota are obvious at the time of diagnosis of ALL. During intensive chemotherapy, dysbiosis persists, and after treatment, the microbiota restores its diversity. However, there are significant gaps in understanding the impact of gut microbiota on the severity of treatment complications and overall survival rate.
\end{abstract}

\section{Hosted file}

manuscript_.doc available at https://authorea.com/users/436440/articles/538750-changes-tothe-gastrointestinal-microbiota-in-pediatric-acute-lymphoblastic-leukemia-a-literaturereview 